\title{
Comparison of Phenol Red and Polyethyleneglycol as Nonabsorbable Markers for the Study of Intestinal Absorption in Humans
}

\author{
Arthur B. French, M.D., Isabel F. Brown,* \\ Chrustopher J. Good, M.B., M.R.C.P., $†$ and \\ GrahaM M. MCLEOD, M.B. (N.Z.), M.R.C.P., M.R.A.C.P.
}

THE USE of biologically inert marker compounds to study the functions of I the human gastrointestinal tract is not new. Markers have been used as qualitative indicators for measuring the time of passage in the gastrointestinal tract for many years. More recently, markers have been used for the quantitative estimation of dilution, ${ }^{1-3}$ transit, 4 and absorption ${ }^{5,6}$ of fed or infused meals or test solutions. Provided a suitable marker compound is used, quantitative estimation of volume change from the ratio of concentration of marker infused to concentration of marker recovered permits reasonably accurate calculation of absorption of a fed or infused nutrient without the necessity of complete recovery of intesinal contents. Limitations of these technics have been explored, ${ }^{7-9}$ and it is clear that the validity of each individual technic must be established. Although the suitability of the marker may vary with each technic, certain general criteria must be met for all technics. A suitable marker compound must: (I) not be absorbed by the segment of gastrointestinal tract under study enough to modify results of the study; (2) be distributed homogeneously among the gastrointestinal contents at all points between introduction and recovery; (3) be physiologically inert with respect to the metabolic processes encountered in the study; (4) be nontoxic for the concentrations and total amounts used and (5) be easily and accurately measured in the fluids with which the study is concerned.

For perfusion studies of the absorption of nutrient from limited segments

From the Department of Internal Medicine. Gastroenterology Section, University of Michigan Medical School, Ann Arbor, Mich. Studies were carried out in part on patients hospitalized in the Clinical Research Unit of The University of Michigan Hospital.

Supported by Grant FR-42 from the Division of Research Facilities and Resources, National Institutes of Health, U. S. Public Health Service. Studies were also supported by Grant AM-07120 from the National Institute for Arthritis and Metabolism, National Institutes of Health, and by a research grant from Parke, Davis and Company.

*Joseph Goldberger Fellow in Nutrition, 1964, at The University of Michigan, supported by the AMA Council on Foods and Nutrition and the Nutrition Foundation, Inc.

†Present address: Royal East Sussex Hospital, Sussex, England.

†Present address: Clinical Research Fellow, Medical Research Council, Department of Gastroenterology, Central Middlesex Hospital, London, England. 
of human intestine, the two most commonly used markers have been phenol red (phenolsulfonphthalein, PSP) and polyethyleneglycol of molecular weight 4000 (PEG). Studies have shown that these compounds are poorly absorbed. However, although the amount of PSP absorbed by the human intestine is too small to invalidate perfusion studies of absorption from short segments of human intestine, enough is absorbed by the entire gastrointestinal tract to be easily demonstrable by measuring urinary excretion. ${ }^{10}$ Studies of PEG absorption have shown essentially complete recovery from small intestinal contents of animals ${ }^{11,12}$ and man $(97 \pm 3 \%), 13$ although stool recoveries usually are less than $90 \%$ of the administered amount. Although PEG 1000 and PEG 6000 are present in human urine after intravenous administration, ${ }^{14}$ PEG 4000 is not found in urine in measurable quantities after oral administration. ${ }^{15}$ Proof that PEG 4000 is not absorbed by the human intestine is not unequivocal, but it is clear that the amount of either PSP or PEG absorbed by a limited (15$100 \mathrm{~cm}$.) segment of human small intestine is negligible in relation to the amounts used as markers.

Further validation of the use of an "unabsorbable" marker compound can be obtained by comparing the dilution or intestinal absorption indicated by each marker when two markers are used simultaneously. If each marker indicates the same proportional dilution, then (1) neither marker is absorbed to an extent great enough to modify results, or (2) each marker is absorbed or otherwise modified to exactly the same extent. When the molecular size and shape of the two marker compounds are quite different, the second possibility becomes unlikely. The present study compares apparent intestinal absorption as indicated by simultaneous use of PSP and PEG as marker compounds. It has been previously reported in abstract. ${ }^{16}$ The current interest in this topic is indicated by similar results recently reported. ${ }^{15}$

\section{MATERIALS AND METHODS}

The comparisons reported in this paper were obtained during perfusion studies of absorptive capacity for dextrose in limited segments of human intestine. The studies were designed to demonstrate reproducibility of the perfusion technic and to compare results of discrete sampling with results of continuous monitoring of the effluent. Results, therefore, include more than one perfusion study for several of the patients. Included are 5 perfusions in 3 subjects with normal intestinal absorption and 3 perfusions in 2 patients with nontropical sprue. Intestinal perfusion studies were carried out using a double-lumen tube in the jejunum. The upper (infusion) opening was just beyond the ligament of Treitz and the lower (recovery) opening $15 \mathrm{~cm}$. further down the jejunum. Solutions were infused at a rate of $13-20 \mathrm{ml} . / \mathrm{min}$. by means of a Harvard peristaltic pump. Infusion rate was constant for each study. Solutions infused contained dextrose concentrations ranging from 3 to $108 \mathrm{gm} . / \mathrm{L}$. in water or 3 to $54 \mathrm{gm}$./L. adjusted to 308 mosm./L. with Krebs 
Henseleit solution. Each solution contained $0.03 \mathrm{mg} . / \mathrm{ml}$. of PSP and $10 \mathrm{mg} . / \mathrm{ml}$. of PEG. Results with the aqueous and saline perfusing solutions are reported separately. A total of 60 perfusion periods were studied. In each period, a single concentration of dextrose was infused for $20 \mathrm{~min}$. of equilibration followed by collection of 3 samples of intestinal effluent. Sample collection time was $1.5-5$ min., as required to obtain 5-ml. samples. Figures and statistical calculations are based on average absorption for each period derived by averaging apparent absorption calculated independently from each of 3 samples. Although intestinal absorptive capacity for dextrose varied greatly between normals and patients with malabsorption, preliminary computer analysis showed no evidence that the relationship between the two marker compounds differed between these groups; therefore, both groups were considered together.

Constant monitoring of the effluent by means of a four-channel Technicon Auto-Analyzer at the patient's bedside produced a continuous record of apparent absorption. Splitting of the effluent from the patient produced the discrete samples used in this analysis. Discrete samples were analyzed for PSP by Technicon Auto-Analyzer, diluting samples and standards with $0.1 \mathrm{M}$

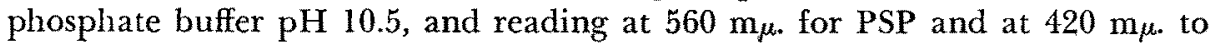
correct for bile pigment (PSP $=$ O.D. at $560 \mathrm{~m}_{\mu}-0.065 \times$ O.D. at $420 \mathrm{~m}_{\mu}$.) . It was unusual for the correction of bile pigment to exceed 0.01 O.D. units when dextrose was the nutrient. Details of factors affecting this method will be presented elsewhere. ${ }^{17}$ PEG was analyzed turbidimetrically using the method of Hydén. ${ }^{18}$ To obtain a colorimeter with a broad band of white light comparable to that used by Hyden, the grating was removed from a Coleman Junior spectrophotometer. A detailed discussion of limitations of analytic methods for PEG will be presented elsewhere. ${ }^{19}$ The presence of PSP did not affect the turbidity of PEG solutions after addition of trichloracetic acid. Regression equations, computer calculated by the method of least squares, for PEG calibration curves at $10 \mathrm{~min}$. in the presence of varying amounts of PSP are given in Table 1. The PSP concentration of $0.0024 \mathrm{mg}$. in the cuvet is equivalent to the effluent concentration of $0.03 \mathrm{mg}$. PSP $/ \mathrm{ml}$. which indicates no net water movement in our perfusion studies.

TABLE 1. REGRESSION EQUATIONS FOR PEG CALIBRATION CURVES IN THE PRESENCE OF PHENOL RED

\begin{tabular}{ccc}
\hline $\begin{array}{c}\text { Phenol red in cuvette } \\
(\mathrm{mg})\end{array}$ & Equation* & $\begin{array}{c}\text { Correlation } \\
\text { coefficient }\end{array}$ \\
\hline 0.0000 & $\mathrm{y}=(.371 \pm .004) \mathrm{x}+.043 \pm .014$ & .995 \\
0.0016 & $\mathrm{y}=(.452 \pm .013) \mathrm{x}+.005 \pm .007$ & .994 \\
0.0024 & $\mathrm{y}=(.375 \pm .005) \mathrm{x}+.047 \pm .013$ & .995 \\
0.0032 & $\mathrm{y}=(.373 \pm .008) \mathrm{x}+.047 \pm .009$ & .996 \\
0.0048 & $\mathrm{y}=(.376 \pm .005) \mathrm{x}+.052 \pm .013$ & .995 \\
\hline
\end{tabular}

*O.D. units are indicated by $y$; PEG concentration in milligrams per milliliter, by $x$. 


\section{RESULTS}

For each period, average apparent absorption for both markers was derived by combining independent calculations of apparent absorption from 3 samples. Average apparent absorptions are shown in Fig. 1 and 2. Regression equations calculated from these data are presented in Table 2. Results were remarkably
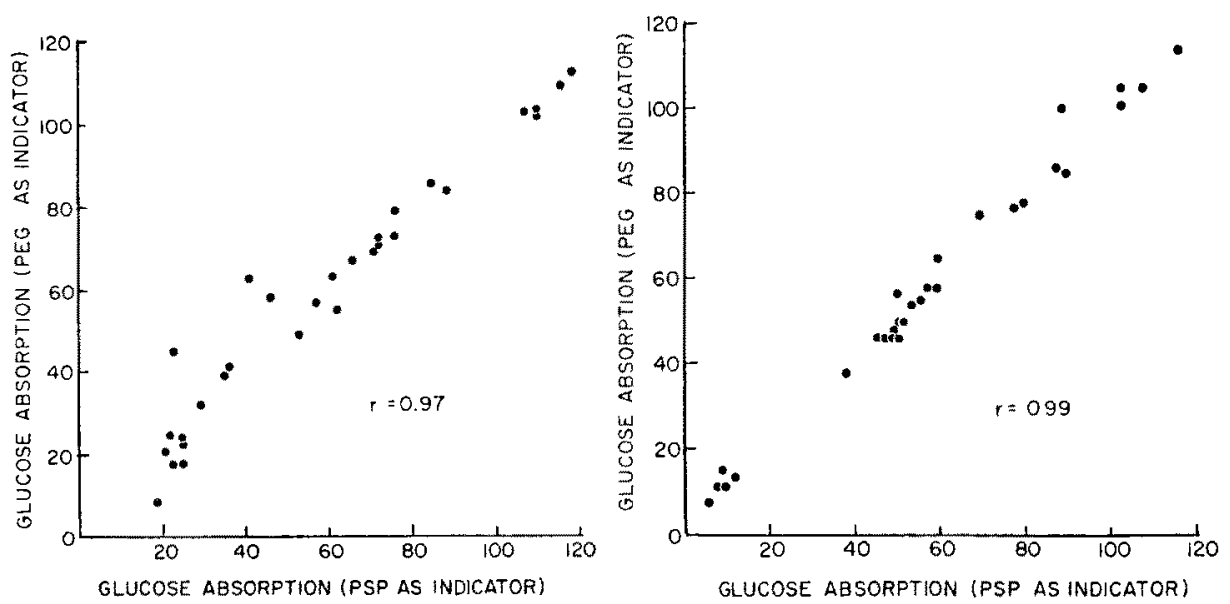

Fig. 1 and 2. Comparison of dilution indicators for measuring glucose absorption by perfusion technic (humans). Fig. 1 (left). Nutrient, glucose in water. Fig. 2 (right). Nutrient, glucose in saline.

similar whichever marker was used. Use of an average figure for each period, instead of individual figures for each sample, minimizes random analytical variability, but retains systematic variability such as that due to differences between the markers. No such difference was found. Results were less variable when the nutrient was dissolved in saline, but whether in water or in saline, both markers indicated essentially the same apparent dextrose absorption. In each case, the intercept of the regression line was indistinguishable from zero and its slope was indistinguishable from $\mathrm{y}=\mathrm{x}$.

TABLE 2. REGRESSION EQUATIONS TO COMPARE APPARENT ABSORPTIONS CALCULATED INDEPENDENTLY WITH THE TWO MARKERS

\begin{tabular}{|c|c|c|}
\hline Samples & Equation* & $\begin{array}{c}\text { Correlation } \\
\text { coefficient }\end{array}$ \\
\hline Dextrose in water & $y=(.920 \pm 0.44) x+5.29 \pm 7.68$ & .972 \\
\hline Dextrose in saline & $y=(.970 \pm .015) x+2.03 \pm 2.40$ & .997 \\
\hline \multicolumn{3}{|l|}{ Monitor PSP } \\
\hline composite & $y=(1.029 \pm .030) x+0.90 \pm 6.85$ & .975 \\
\hline
\end{tabular}

*Apparent absorption in milligrams per minute per segment on the $x$ axis as indicated by PSP and on the $y$ axis as indicated by PEG. 


\section{DISCUSSION}

This agreement between apparent absorption as indicated by two independent "nonabsorbable" markers supports the evidence that either phenol red or polyethyleneglycol 4000 is an appropriate reference compound. This evidence indicates that neither is absorbed to an extent that interferes with its use as a dilution indicator in perfusion studies of dextrose absorption in limited segments of human jejunum. The present results are similar to comparisons of PEG and PSP in humans obtained by others ${ }^{15,20}$ and in contrast to comparisons of $\mathrm{PEG}$ and BSP in rabbit and dog. ${ }^{7}$ The latter dye probably is absorbed to a greater extent and more variably than is PSP. Before applying the results of these comparisons, obtained under the specific conditions of intestinal perfusion with water-soluble nutrients, to other methods of studying intestinal function, one must consider possible limitations. PSP is unquestionably absorbed from both normal and abnormal intestine in small amountsabout $1 \%$ of an oral dose per hour from the entire gastrointestinal tract. ${ }^{10}$ This is too small to detect in our calculations as a systematic variation within the random physiological and analytical variations present in our results. The "general tendency for slightly higher values for P.R.C. than for P.E.G." (where P.R.C. is ratio of PSP-in/PSP-out with corrections for background) noted by Sched15 was only $1 \%$ higher and well below the level of statistical significance. Our use of averages of 3 samples collected during infusion of each glucose concentration decreases the random biological variation present in his results, while it retains any systematic variation which might be due to unequal absorption of markers. It is reasonable to conclude that in normal subjects and in patients with intestinal malabsorption, absorption of PEG and PSP by the intestine does not interfere with their use as markers. Although absorption of PSP from the stomach does occur when contents are acid $^{21}$ and may be as high as $40 \%$ of PSP infused in a patient with Zollinger-Ellison syndrome, ${ }^{22}$ total absorption from both stomach and intestine is usually less than 1\%/hr. ${ }^{10}$ Absorption, including absorption of PSP from the small intestine, may be modified by the presence of butyric acid ${ }^{23}$ or EDTA. ${ }^{24}$ The effect of such substances on the absorption of other marker compounds has not been reported. Separation of various components of intestinal contents invalidates the use of nonabsorbable markers unless marker and the nutrient act similarly. Casein and other proteins bind PSP25 but not PEG.7 This as well as PSP absorption from the stomach produced the dissociation between the markers PEG and PSP found by Wiggins and Dawson. ${ }^{26}$ Other instances of marker dissociation have been noted when an insoluble marker such as $\mathrm{Cr}_{2} \mathrm{O}_{3}$ was compared with water soluble PEG; however, they may remain together and give good correlation of fecal recoveries of the two markers. ${ }^{27,}{ }^{28}$ The excellent correlation shown in this study indicates that, despite the dissimilarity in molecular structure of PSP and PEG, these two markers did not dissociate in the presence of water soluble nutrient with and without water soluble salts. 


\section{SUMMARY}

When phenol red and polyethyleneglycol were used simultaneously as nonabsorbable markers in perfusion studies of the absorptive capacity of high jejunum in humans, apparent absorption was the same when calculated from either marker. This similar indication of dilution and of absorption by the two markers was found in normal subjects and in patients with nontropical sprue, whether aqueous or saline solutions of dextrose were infused. The similarity strengthens the evidence that either phenol red or polyethyleneglycol is a satisfactory "nonabsorbable" marker compound to indicate dilution in perfusion studies of dextrose and electrolyte absorption in limited segments of human intestine.

Clinical Research Unil

W46+4 University of Michigan Hospital Ann Arbor, Mich. 48104

\section{REFERENGES}

1. GorhaM, F. D. Factor of dilution in gastric analysis. JAMA 81:1738. 1923.

2. Hunt, J. N., and Spurrel, W. R. Patterns of emptying of the human stomach. $J$ Physiol $113: 157,1951$.

3. Lagfrlör, H. O., Rudewat.d, M. B., and PERman, G. Neutralization process in duodenum and its influence on gastric emptying in man. Acta Med Scand 168:269, 1960.

4. Dillard, R. L., Eastman, H., and Forbtran, J. S. Volume-flow relationship during the transport of fluid through the human small intestine. Gastroenterology 49:58, 1965.

5. Borgström, B., Dahlovist, A., Lundr, G., and Sjövall, J. Studies of intestinal digestion and absorption in the human. I Clin Invest 36:1521, 1957.

6. Hendrix, T. R. Effect of a hypertonic solution on intestinal absorption. Amer $J$ Dig Dis $2.643,1957$.

7. Jacobson, E. D., Bondy, D. C., Broitman, S. A., and Fordtran, J. S. Validity of polyethyleneglycol in estimating water volume. Gastroenterology 41:761, 1963.

8. Whalen, G. E., Harris, J. A., Gennen, J. E., and Sorrgel, K. H. Sodium and water absorption from the human small intestine: The accuracy of the perfusion method. Gastroenterology 51:975, 1966.

9. Worning, H., and Amdrup, E. Experimental studies on the value of the reference substances, polyethyleneglycol, bromsulphthalein, and ${ }^{81} \mathrm{Cr}$ as indicators of the fuid content in the intestinal lumen. Gut $6: 487,1965$.

10. MCLeod, G. M., Frfnch, A. B., Good, C. I., and Wricht, F. S. Gastrointestinal absorption and biliary excretion of phenolsulfonphthalein (phenol red) in man. I Lab Clin Med $71: 192,1968$.

11. Hyoín, S. Recovery of polyethyleneglycol after passage through the digestive tract. Kungl Lantbr-Högsk Ann 22:411, 1956.

12. Smrt, R. H. Net exchange of certain inorganic ions and water in the alimentary tract of the milk-fed calf. Biochem J 83:151, 1962.

13. Solergel, K. H., and Hogan, W. J. On the suitability of poorly absorbed markers as dilution indicators in the gastrointestinal tract, Gastroenterology 52:1056, 1967.

14. Shaffer, C. B., and Critchfield, F. H. Absorption and excretion of the solid polyethylene glycols "Carbowax" compounds). I Amer Pharm Ass 36:152, 1947.

15. Scheds, H. P. Use of polyethyleneglycol and phenol red as unabsorbed indicators for intestinal absorption studies in man. Gut $7: 159,1966$.

16. French, A. B., Goon, C. J, and McLeod, G. M. Factors affecting results of intestinal perfusion technique for study of intestinal absorption in humans. Fed Proc 24:652, 1965.

17. Frinch, A. B., Wricht, F. S., Good, C. J., Mcleon, G. M., Cook, H. B., Dickason, B. A., and I.E Duc, H. M. Intestinal perfusion techniques for measuring absorptive capacity of limited segments of human small intestine. Unpublished data. 
18. HYDÉN, S. Turbidimetric method for the determination of higher polyethyleneglycols in biological materials. Kungl Lantbr.Högsh Ann 22:139, 1955.

19. Brown, I. F., Wrgerns, H. S., and FrenCH, A. B. Factors affecting analysis of polyethyleneglycol. Unpublished data.

20. SCHEDt, H. P., and Clifton, J. A. Solute and water absorption by the human small intestine. Nature 199:1264, 1963.

21. Bloom, D. S., Jacobson, E. D., and Grossman, M. I. Validation of dilution indicators in the stomach, Gastroenterology 52:205, 1967.

22. Cook, H. B., and French, A. B. Physiological responses to gastric acid by hypersecretion in Zollinger-Ellison syndrome. Amer J Dig Dis 13:191, 1968.

23. Levine, $R$. R. Influence of the intraluminal milieu on absorption of an organic cation and an anionic agent. $J$ Pharmacol Exp Ther 131:328, 1961.

24. Tinball, C. S., and Peterson, K. K. Changes in intestinal net water movement and phenolsulfonphthalein absorption produced by ethylenediaminetetraacetic acid. Physiologist 4:121, 1961.

25. Grollman, A. Combination of phenol red and proteins. J Biol Chem 64:141, 1925.

26. Wigcrns, H. S., and DAwson, A. M. Evaluation of unabsorbable markers in the study of fat absorption. Gut 2:273, 1961.

27. IsHKawA, S. Reliability of polyethylene glycol as an indicator for digestion studies with swine. 1. Rate of passage of polyethyleneglycol through the digestive tract. $\mathrm{Agr}$ Biol Chem 30:278, 1966.

28. Corbett, J. L., Greenhalgh, J. F., Gwinn, P. E., and Walker, D. Excretion of chromium sesquioxide and polyethyleneglycol by dairy cows. Brit J Nulr 12:266, 1958. 